\title{
Oxytocin is a cardiovascular hormone
}

\section{J. Gutkowska1, M. Jankowski ${ }^{1}$, \\ S. M ukaddam-Daher ${ }^{1}$ and S.M. McCann²}

\author{
${ }^{1}$ Laboratory of Cardiovascular Biochemistry, \\ Centre Hospitalier de I'U niversité de Montréal, Hôtel-Dieu, \\ Department of M edicine, University of M ontreal, M ontreal, Canada \\ 2Pennington Biomedical Research Center, Louisiana State University, \\ Baton Rouge, LA, USA
}

\section{Correspondence \\ J. Gutkowska \\ Laboratory of Cardiovascular \\ Biochemistry \\ Research Centre, CHUM, Hôtel-Dieu \\ 3850 St. U rbain Street \\ Masson Pavilion, Montreal \\ Canada H 2 W 1 T8 \\ Fax: + 1-514-843-2715 \\ E-mail: \\ jolanta.gutkowska@umontreal.ca}

Presented at the III International Symposium on Vasoactive Peptides, Belo Horizonte, MG, Brasil, O ctober 8-10, 1999.

Research supported by the Medical Research Council of Canada, MT. 11674 and MT-14410 to J. Gutkowska, and MT-15049 to M. Jankowski.

Received November 26, 1999 Accepted February 2, 2000

\section{Abstract}

Oxytocin (OT), a nonapeptide, was the first hormone to have its biological activities established and chemical structure determined. It was believed that OT is released from hypothalamic nerve terminals of the posterior hypophysis into the circulation where it stimulates uterine contractions during parturition, and milk ejection during lactation. However, equivalent concentrations of OT were found in the male hypophysis, and similar stimuli of OT release were determined for both sexes, suggesting other physiological functions. Indeed, recent studies indicate that OT is involved in cognition, tolerance, adaptation and complex sexual and maternal behaviour, as well as in the regulation of cardiovascular functions. It has long been known that OT induces natriuresis and causes a fall in mean arterial pressure, both after acute and chronic treatment, but the mechanism was not clear. The discovery of the natriuretic family shed new light on this matter. Atrial natriuretic peptide (ANP), a potent natriuretic and vasorelaxant hormone, originally isolated from rat atria, has been found at other sites, including the brain. Blood volume expansion causes ANP release that is believed to be important in the induction of natriuresis and diuresis, which in turn act to reduce the increase in blood volume. Neurohypophysectomy totally abolishes the ANP response to volume expansion. This indicates that one of the major hypophyseal peptides is responsible for ANP release. The role of ANP in OT-induced natriuresis was evaluated, and we hypothesized that the cardio-renal effects of OT are mediated by the release of ANP from the heart. To support this hypothesis, we have demonstrated the presence and synthesis of OT receptors in all heart compartments and the vasculature. The functionality of these receptors has been established by the ability of OT to induce ANP release from perfused heart or atrial slices. Furthermore, we have shown that the heart and large vessels like the aorta and vena cava are sites of OT synthesis. Therefore, locally produced OT may have important regulatory functions within the heart and vascular beds. Such functions may include slowing down of the heart or the regulation of local vascular tone.

\section{Key words} - Oxytocin

- Natriuretic peptides

- Heart ....................... 
"It does not seem justifiable... to draw... the conclusion that the principle acting on the plain muscle of the uterus is different from that which acts on the arteries".

Henry Dale: The actions of extracts of pituitary body. Biochemistry Journal (1910), 4: 427-447.

\section{Introduction}

The first description of the uterotonic action of pituitary extracts was given by Sir Henry Dale in 1906 (1). A few years later, Ott and Scott (2) showed that beside their effect on uterine activity, the posterior pituitary extracts also promote milk ejection the two principal activities of oxytocin (OT), the structure and synthesis of which were not elucidated until 50 years later by du Vigneaud and co-workers (3).

OT is synthesized in magnocellular neurons with cell bodies in the supraoptic and paraventricular nuclei of the hypothalamus and axons that project to the neurohypophysis where it is stored and released into the circulation.

It was believed that OT as well as arginine vasopressin (AVP) were exclusively released from the neurohypophysis although Ott and Scott (2) reported that the extracts of other tissues such as corpus luteum, pineal and thymus glands have the same milk-ejecting properties. These observations were completely overlooked. However, recent studies have shown that oxytocin is a ubiquitous hormone, synthesized at many sites, and a great array of physiological activities has been attributed to this peptide.

Indeed, there is substantial evidence that OT is an important hormone to induce sexual and maternal behaviour or cognitive and cardiovascular functions.

The hypothesis that oxytocin subserves other physiological functions emerged from the fact that the circulating level of OT and the number of oxytocinergic neurons in the hypothalamus are sex-independent (4). Fur- thermore, stimuli such as increases in osmolality, hypovolemia or angiotensin II, enhance the release of OT in females and males in the same way. Oxytocin is associated with reproduction not only in female rats but also in males. In both sexes, oxytocin administered chronically increases non-sexual social interactions.

It has long been recognized that oxytocin increases renal electrolyte excretion in various species, and that the natriuretic and kaliuretic effects are vasopressin-independent. There is evidence that OT produces natriuresis in rats at physiological plasma levels, and that elevated plasma OT levels correlate with increased sodium excretion (5).

Intracerebroventricularly injected OT decreased blood pressure, whereas inhibition of brain OT synthesis by an anti-sense oligonucleotide increased blood pressure in rats (6). In primates, humans, and rats the administration of oxytocin is often associated with a decrease in blood pressure $(7,8)$. The mechanism by which OT induces cardiovascular effects is not yet known.

We hypothesized that regulation of cardiovascular functions by OT is mediated by the atrial natriuretic peptide (ANP) (9). ANP is a potent diuretic, natriuretic and vasorelaxant hormone originally found in the heart atria but also present in the brain and various peripheral tissues. This hypothesis is based on several original and unique observations made as a result of the studies on the role of the brain in ANP release, and on our recent finding of OT and oxytocin receptors (OTR) in the heart.

\section{Neural control of hydromineral homeostasis}

Central control of volume regulation is believed to reside in the anteroventral third ventricle $(\mathrm{AV} 3 \mathrm{~V})$ area; however, this area is part of a neuronal circuit that includes the septal area, amygdaloid complex and hypothalamus. ANP neurons (with cell bodies in 
the paraventricular nucleus projecting axons to the external layer of the median eminence (ME) and to the neural lobe) are important in AV3V mediated natriuresis (10). Cholinergic and adrenergic stimulation of AV3V increases sodium excretion, which is associated with a rapid increase in plasma ANP. Destruction of the AV3V inhibits sodium excretion and results in a dramatic decrease in plasma ANP as well as ANP in some brain areas, without changes in blood pressure or heart rate (10). Further, ME lesions largely inhibit and neurohypophysectomy abolishes the volume expansion-induced ANP release (11). These observations led to the hypothesis of a pituitary factor inducing ANP release from the atria. Vasopressin has already been shown to stimulate ANP but only at doses that increase blood pressure, indicating a haemodynamic effect (12). Therefore, we considered the possibility that oxytocin released from the hypophysis circulates to the heart and induces ANP release. Indeed, there is evidence that oxytocin triggers ANP release in vivo (13).

\section{Natriuretic action of oxytocin}

It has been long recognized that OT influences renal excretion of electrolytes. Acutely hypophysectomized rats exhibit marked retention of sodium (14) and a decline in blood pressure and glomerular filtration rate (GFR) probably due to the loss of pituitary function (15). Further work of Balment et al. (16) showed that neurohypophysectomized rats avidly retain sodium in a manner similar to that observed in acutely hypophysectomized rats, implicating posterior pituitary factors in the sodium retention following hypophysectomy.

The acute renal actions of OT include increased GFR, filtration fraction and sodium excretion without affecting potassium excretion (17) in Brattleboro rats with a hereditary lack of AVP (18), which suggests that OT exerts renal actions independent of vasopressin. Oxytocin also has tubular actions (19) on apical sodium conductance that may be related to increases in intracellular $\left[\mathrm{Ca}^{2+}\right]$ and cAMP production (20). It has been suggested that at least part of the OTinduced natriuresis is mediated by the kallikrein-kinin system (21).

Very early experiments on the renal effects of OT conducted in dogs indicated that OT increases sodium excretion at low urine flow, and at the same time may act as an antidiuretic substance in water-loaded dogs. Furthermore, Chan and Sawyer (22) also found that high doses of OT induced natriuresis in water-loaded dogs.

Recent research of Verbalis et al. (5) showed that OT produces natriuresis in conscious rats at physiological plasma concentrations. Subcutaneous infusion of graded doses of OT, causing an increased plasma OT level within the physiological range, increased urinary sodium excretion in conscious rats maintained on a low sodium diet. This effect was blocked by an OTR antagonist, was not affected by a vasopressin $\mathrm{V}_{1}$ antagonist and was partially inhibited by a combination of $\mathrm{V}_{1}$ and $\mathrm{V}_{2} \mathrm{AVP}$ antagonists.

It has been thought that the natriuretic effect of OT was mediated by specific renal OTR. However, very early observations of Sedlakova et al. (23) indicated that at least part of the natriuretic effect of OT may result from secondary rather than primary hormonekidney interaction. The natriuresis produced by OT and OT analogs was several-fold greater when the substances were injected into the carotid than into the renal artery. Furthermore, in the isolated perfused dog kidney, OT failed to induce any natriuresis. Therefore, it appears that OT causes the release of a substance that decreases sodium reabsorption.

We have strong evidence that ANP is that substance and that OT-induced renal actions are mediated at least in part by ANP, a potent diuretic, natriuretic and vasorelaxant hormone synthesized in the heart atria and at 
many other sites $(9,24)$.

\section{Natriuretic peptide family}

The natriuretic peptides, atrial (ANP), brain (BNP) and C-type (CNP), act via endocrine and paracrine/autocrine mechanisms as one of the key modulatory systems for blood pressure regulation and body fluid homeostasis $(9,25,26)$. The natriuretic peptides inhibit proliferation and hypertrophy of vascular smooth muscle cells and endothelial cells through cGMP production (27). ANP plays an integral role in the regulation of hydromineral homeostasis under normal and pathological conditions through potent biological effects, including vasorelaxation, diuresis and natriuresis, and reduction of venous return by a shift of plasma into the interstitium. The natriuretic and diuretic actions of ANP result from enhanced GFR and/or reduced tubular reabsorption of sodium and water, as well as suppression of renin, aldosterone and vasopressin, and antagonism of most of the peripheral and central actions of angiotensin II (28).

$\mathrm{BNP}$ is secreted predominantly from the cardiac ventricles in a constitutive manner in response to increased pressure or stretch of the ventricles. Plasma BNP levels are normally lower than ANP, but increase by 100 fold in heart failure, where its levels in plasma provide an index of cardiac dysfunction. The biological actions of BNP mirror those of ANP, i.e., diuretic and natriuretic properties, as well as reduction of renin and aldosterone secretion.

CNP (22 amino acids) shows remarkable homology to ANP and BNP within the 17amino acid ring structure. CNP originally isolated from porcine brain (26) and shown as a neurotransmitter is now considered an important component of peripheral tissues including vascular endothelium (29) and ovaries (30). The actions of CNP are different from those described for ANP and BNP. $\mathrm{CNP}$ does not show any diuretic or natriuret- ic actions in dogs and humans while it induces potent hemodynamic effects (31). Also, in contrast to ANP, CNP stimulates prolactin secretion with a hypothalamic site of action (32) and stimulates rather than inhibits water drinking in rats (33). The place of CNP in physiology and pathophysiology is much less clear than that of ANP and BNP.

The biological actions of natriuretic peptides are mediated by specific guanylyl cyclase receptors (GC-A and GC-B) through generation of cGMP (34-36). The ligand selectivity of GC-A is ANP $\geq \mathrm{BNP}>\mathrm{CNP}$, and that of GC-B is CNP $>A N P \geq B N P$ (37). A third receptor, "C" or NPR-C, does not show any ligand selectivity and thus may promote clearance of the peptides from the circulation (38). NPR-C may also mediate inhibition of endothelin release and antagonism of the renin-angiotensin-aldosterone system (28) via inhibition of adenylyl cyclase (39).

Among the natriuretic peptides, ANP has been the most studied. ANP ( 28 amino acids) is a cardiac hormone released into the circulation primarily by volume expansion and atrial stretch $(40,41)$. In addition, humoral and neuronal factors such as adrenoceptor agonists, calcium channel agonists, arginine vasopressin, angiotensin II, endothelins and opioids have been shown to regulate ANP release, although the hemodynamic effect of these peptides cannot be ruled out (42-44).

We have recently added OT to these factors as a physiologically relevant stimulus of ANP release.

\section{Oxytocin and ANP release}

ANP and OT are colocalized in some hypothalamic magnocellular neurons (45) with the highest percentage $(90 \%)$ of oxytocinergic neurons containing ANP immunoreactivity found in the intersupraopticoparaventricular island. The colocalization of both these peptides provides a morphologi- 
cal basis for their interaction in the modulation of physiological actions.

Oxytocin injected intraperitoneally or intravenously induces dose-related increases in plasma ANP that correlate with increases in sodium and potassium excretion (13). Blood volume expansion with isotonic and hypertonic saline stimulates ANP as well as OT release (46). Suckling, a physiological stimulus for OT release, is also associated with significant increases in plasma ANP. Furthermore, OT induces ANP release from quartered rat atria as well as during isolated heart perfusion (47). An OT antagonist inhibited the stimulated and basal ANP release from perfused rat heart. Therefore, we hypothesized that the OT action on the heart is mediated by specific OTR (48).

\section{Oxytocin system in the heart}

\section{Heart oxytocin receptors}

The oxytocin receptor gene is expressed at various sites of the reproductive tract considered as target sites of OT actions, and in some peripheral tissues such as kidney, pituitary and mammary glands as well as in various brain areas (49). The OTR has been cloned and shown to be a member of OT/ vasopressin receptors that constitute a subclass of $\mathrm{G}$ protein-coupled receptors (50).

We have characterized oxytocin receptors in the rat heart that appear to be identical to those in other organs (48). The presence of OTR in the rat heart was demonstrated by autoradiography performed on frozen sections. The radiolabeled oxytocin antagonist ( ${ }^{125}$ I-OTA) binding was progressively inhibited by increasing quantities of unlabeled OT. The OTR binding affinity was similar in atrial and ventricular receptors, with $\mathrm{Kd} \sim 71$ $\mathrm{pM}$ and $\mathrm{Kd} \sim 30 \mathrm{pM}$, respectively. The number of OTR was also similar in all heart compartments.

The presence of specific transcript for OTR in the rat heart was demonstrated by amplification of cDNA obtained from mRNA of both rat atria and ventricles by PCR using specific oligonucleotide primers. Amplified rat heart OTR sequence was identical to that of rat uterus and hypothalamus, indicating a close structural relationship. The size of the PCR amplification product obtained had the expected molecular size of 373 $\mathrm{bp}$, the same receptor size found in the rat uterus (Figure 1). The RT-PCR did not show any extra band that could indicate the presence of different splicing forms. The presence of OTR transcripts was also shown by in situ hybridization on atrial and ventricular tissues using reverse PCR primers as probe.

Functionality of heart OTR was demonstrated by the ability of OT to release ANP from the isolated perfused heart. Addition of OT $\left(10^{-6} \mathrm{M}\right)$ to the perfusion buffer significantly enhanced ANP release. Oxytocin $10^{-6}$ $M$ resulted in a gradual and significant decrease in heart rate from $330 \pm 12$ to $288 \pm 9$ beats/min. The OTA inhibited ANP release in a dose-related manner. Interestingly, OTA at the concentration of $10^{-6} \mathrm{M}$ decreased ANP release below control levels. This observation implied the existence of intracardiac synthesis of OT.

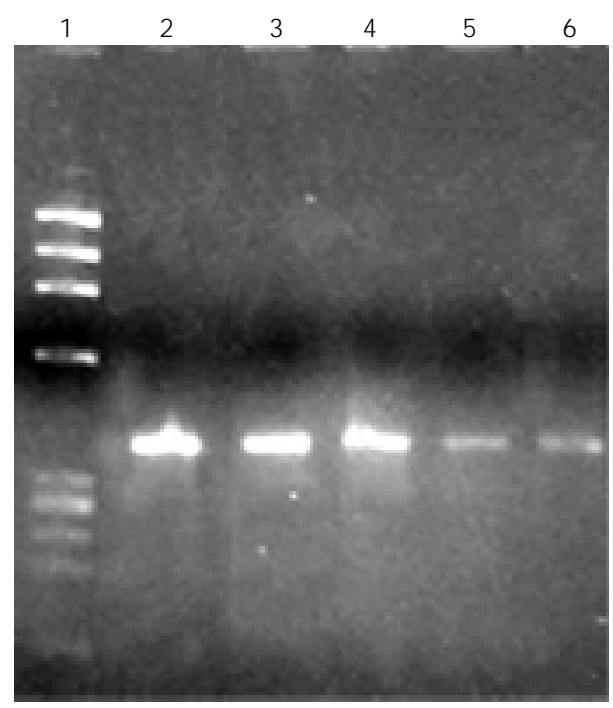

Figure 1 - Detection of oxytocin receptor mRNA in rat heart chambers by RT-PCR. The photograph presents RT-PCR products amplified from cDNA samples after electrophoresis on $2 \%$ agarose in ethidium bromide. Lanes: 1, pBR322 DNA cleaved with Haelll; 2, uterus; 3, right atrium; 4, left atrium; 5, right ventricle; 6 , left ventricle. 


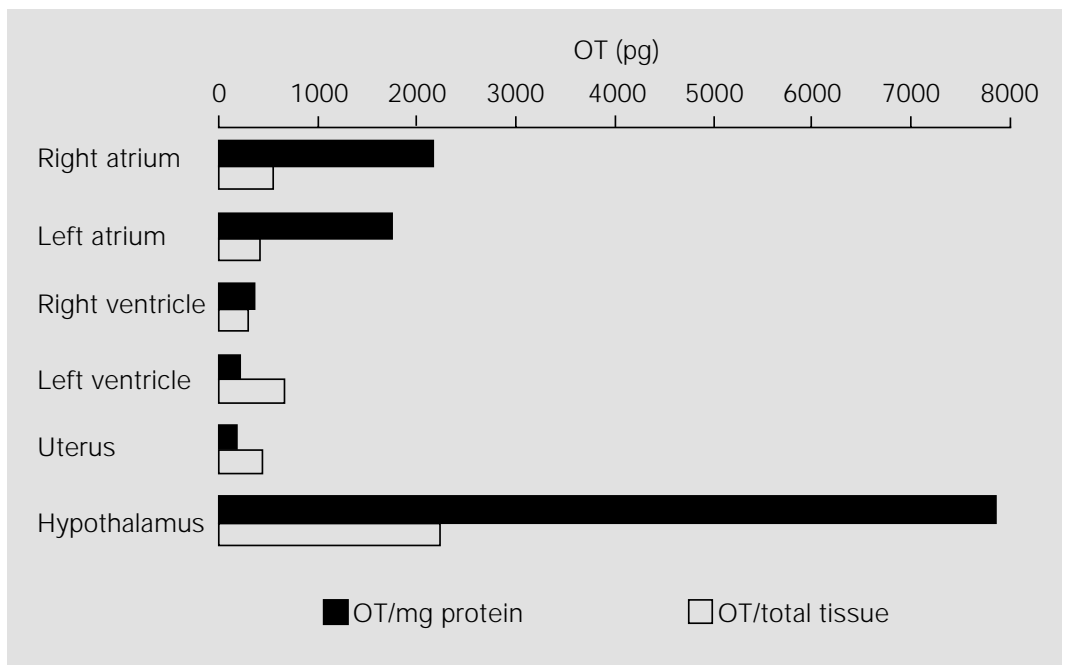

Figure 2 - Oxytocin (OT) concentration in the rat heart chambers vs uterus and hypothalamus obtained by RIA. Data are presented as OT, pg/mg protein, and OT, pg/organ or heart chamber.

Figure 3 - Time-course of oxytocin (OT) secretion from atrial cardiomyocytes in vitro. Medium samples were collected from 6 independent cultures and OT was measured by RIA.

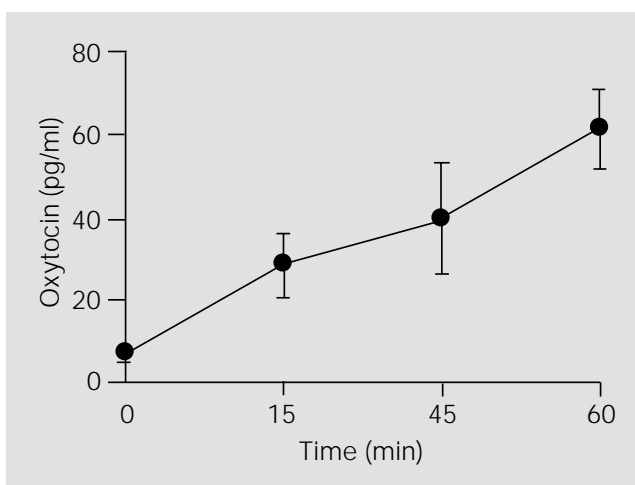

\section{Heart oxytocin}

Indeed, OT is present and synthesized in the heart. The presence of OT was detected by radioimmunoassay in all four chambers of the rat heart (Figure 2). The highest concentration was found in the right atrium (2128 $\pm 114 \mathrm{pg} / \mathrm{mg}$ protein) which is about the same range as found in the hypothalamus (51). Left atrial content was $1739 \pm 16 \mathrm{pg} /$ mg protein. The ventricular OT levels were lower in comparison to atria. In addition, in vitro studies showed OT secretion from atrial myocytes (Figure 3 ) and the presence of OT in heart perfusate. Specific OT transcript was demonstrated in all four heart compartments by the amplification of rat heart cDNA by PCR (Figure 4). The amplified fragments of the OT gene generated from the rat heart chambers are products identical in size to those of the uterus. This finding indicates that OT transcripts are structurally identical in heart and uterus.

\section{Oxytocin in vasculature}

Since we have discovered that OT is produced and released by the heart and acts on its cardiac receptors to decrease cardiac rate and force of contraction, we hypothesized that OT might be produced in the vasculature and dilate vessels. Indeed, our studies show that an intrinsic OT system, sensitive to estrogenic regulation exists in the vasculature. Immunoreactive OT has been identified in rat, sheep and dog vessels by a specific radioimmunoassay, and characterized by HPLC (Figure 5). The RT-PCR analysis identified OT transcripts containing the coding sequence of the OT gene in the aorta (Figure 4) and vena cava. The membrane binding with ${ }^{125}$ I-OTA and detection of OTR mRNA confirmed the presence of OTRs in the vasculature. Estrogen treatment enhanced OT and OTR gene expression in the vena cava, but only OTR mRNA was increased in the aorta.

\section{Summary}

The results presented here demonstrate a functional OT system in the rat heart and vasculature. We have shown the presence of OT mRNA in rat cardiocytes and large vessels. All four heart compartments, as well as large vessels, synthesize OTR, which is regulated by estrogen. The functionality of heart OTR has been shown by the OT ability to release ANP, an effect that was totally inhibited by an OTR antagonist.

We have reasons to believe that local OT production in the heart is physiologically 

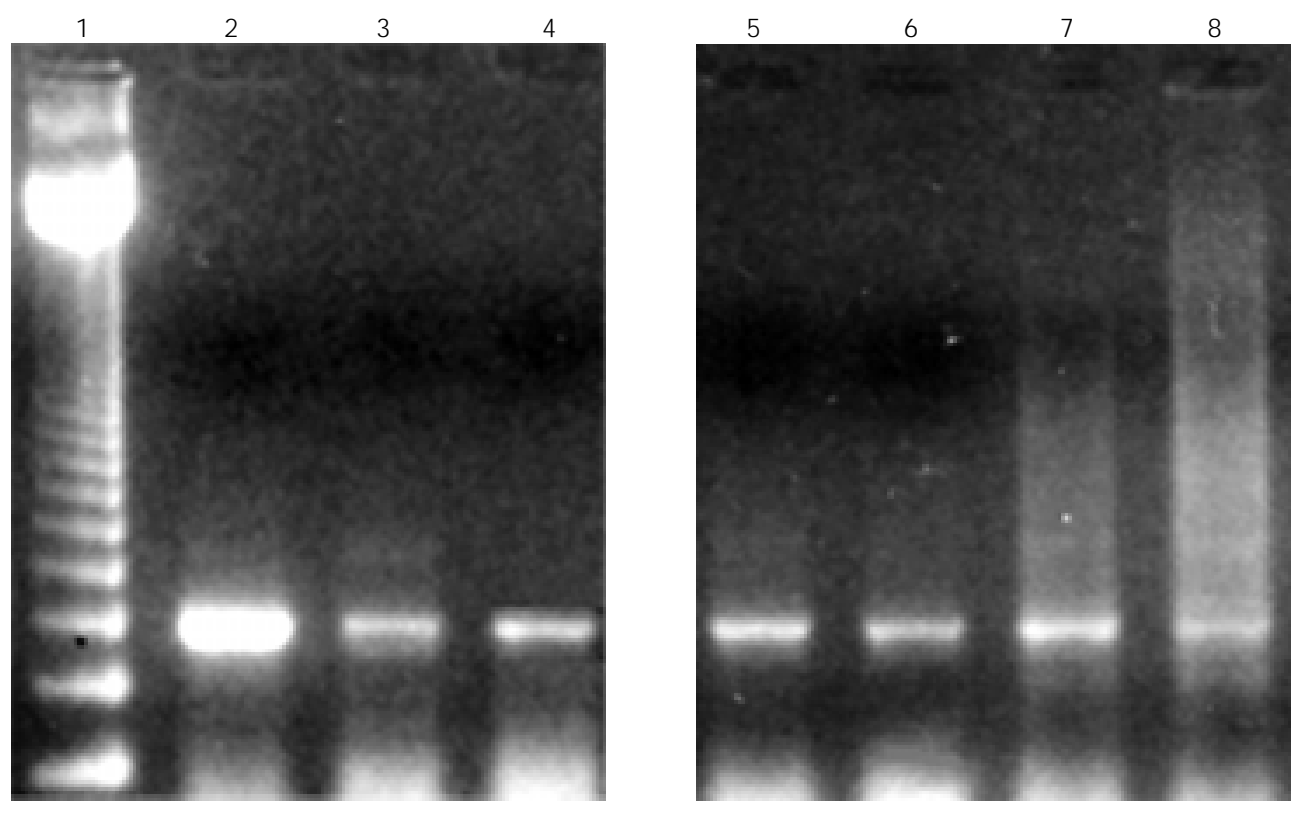

Figure 4 - Detection of oxytocin mRNA in rat heart and aorta by RT-PCR. The photograph presents RT-PCR products amplified from cDNA samples after electrophoresis on $2 \%$ agarose in ethidium bromide. Lanes: 1 , 123-bp ladder Gibco/BRL; 2, uterus; 3 , cultured atrial myocytes; 4 , aorta; 5 , right atrium; 6 , left atrium; 7 , right ventricle; 8 , left ventricle.

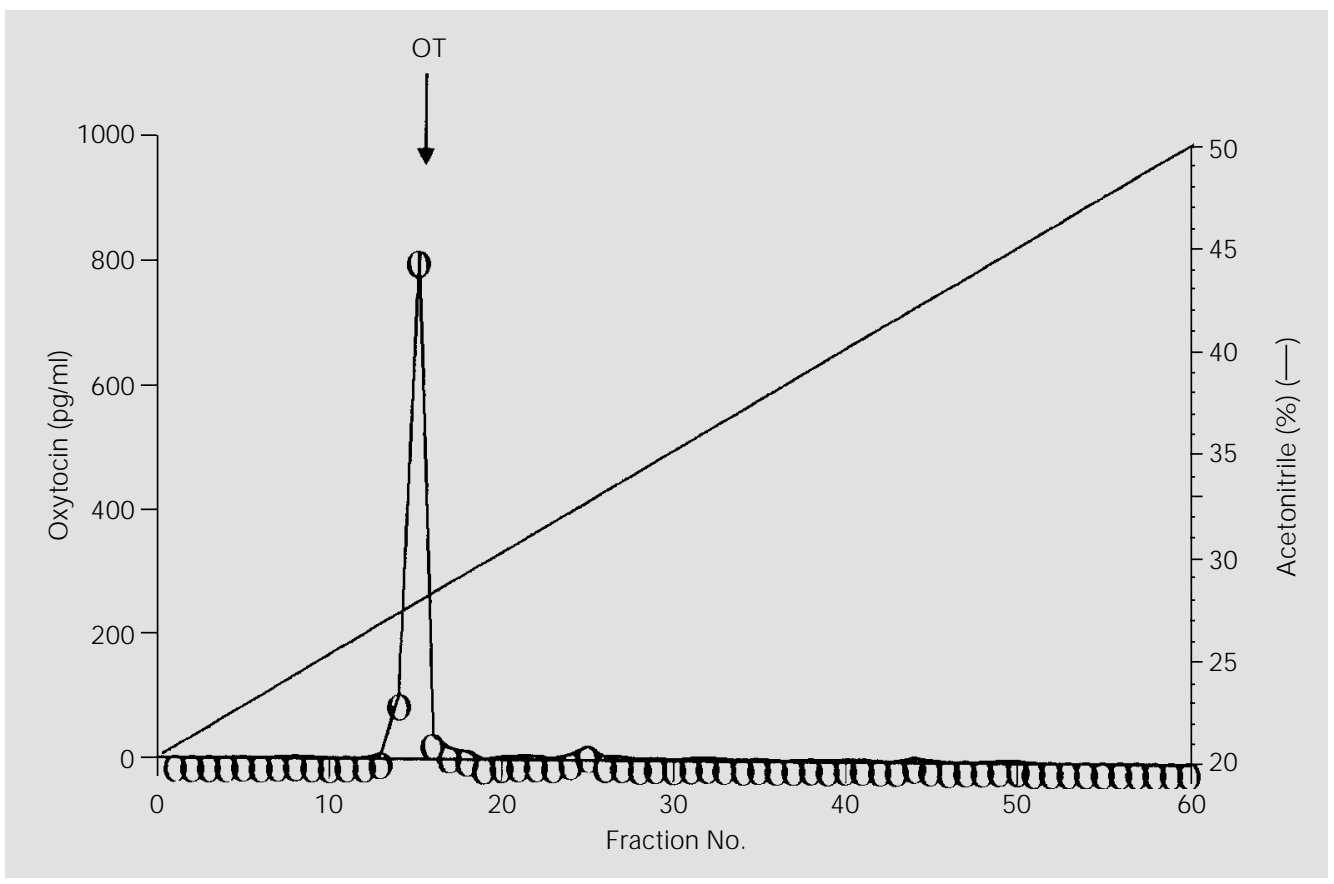

Figure 5 - Reverse-phase HPLC elution profile of oxytocin (OT) immunoreactivity in the dog aorta. Tissue extracts were lyophilized and reconstituted in $20 \%$ acetonitrile in $0.1 \%$ TFA. Oxytocin in eluted fractions was measured by RIA.

relevant. It is conceivable that ANP released through the activation of OTR slows the heart by inducing a negative chronotropic effect. The implication of the presence of the OT system in the large vessels may include local formation of CNP and ANP, which consequently induces vasorelaxation. The indirect OT effect by the release of CNP or ANP may inhibit growth and cell proliferation.

These results support the concept that OT and ANP act in concert to control body fluid and cardiovascular homeostasis. 


\section{References}

1. Dale HH (1906). On some physiological actions of ergot. J ournal of Physiology, 34: 163-206.

2. Ott I \& Scott J C (1910). The action of infundibulin upon the mammary secretion. Proceedings of the Society for Experimental Biology, 8: 48-49.

3. Du Vigneaud V (1956). Hormones of the posterior pituitary gland. Oxytocin and vasopressin. Harvey Lectures, 51: 1-26.

4. Kadekaro $M$, Summy-Long J Y, Freeman S, Harris J S, Terrell ML \& Eisenberg HM (1992). Cerebral metabolic responses and vasopressin and oxytocin secretions during progressive water deprivation in rats (published erratum appears in the American J ournal of Physiology, 1992, 262 (Part 3): Section R following table of contents). American J oumal of Physiology, 262 (Part 2): R310-R317.

5. Verbalis J G, Mangione MP \& Stricker EM (1991). Oxytocin produces natriuresis in rats at physiological plasma concentrations. Endocrinology, 128: 1317-1322.

6. Maier T, Dai WJ , Csikos T, J irikowski GF, Unger T \& Culman J (1998). Oxytocin pathways mediate the cardiovascular and behavioral response to substance $P$ in the rat brain. Hypertension, 31: 480-486.

7. Petersson $M$, Alster $P$, Lundeberg $T \&$ Uvnas-Moberg K (1996). Oxytocin causes a long-term decrease of blood pressure in female and male rats. Physiology and Behavior, 60: 1311-1315.

8. Petersson $M$, Lundeberg $T \&$ UvnasMoberg K (1997). Oxytocin decreases blood pressure in male but not in female spontaneously hypertensive rats. J ournal of the Autonomic Nervous System, 66: 15-18.

9. De Bold AJ , Borenstein HB, Veress AT \& Sonnenberg $H$ (1981). A rapid and potent natriuretic response to intravenous injection of atrial myocardial extract in rats. Life Sciences, 28: 89-94.

10. Baldissera S, Menani JW, Sotero dos Santos LF, Favaretto AL, Gutkowska J , Turrin MQ, McCann SM \& AntunesRodrigues J (1989). Role of the hypothalamus in the control of atrial natriuretic peptide release. Proceedings of the National Academy of Sciences, USA, 86: 96219625.

11. Antunes-Rodrigues J, Ramalho MJ, Reis LC, Menani J V, Turrin MQ, Gutkowska J $\&$ McCann SM (1991). Lesions of the hypothalamus and pituitary inhibit volumeexpansion-induced release of atrial natri- uretic peptide. Proceedings of the National Academy of Sciences, USA, 88: 2956-2960.

12. Manning PT, Schwartz D, Katsube NC, Holmberg SW \& Needleman P (1985). Vasopressin-stimulated release of atriopeptin: endocrine antagonists in fluid homeostasis. Science, 229: 395-397.

13. Haanwinckel MA, Elias LK, Favaretto AL, Gutkowska J, McCann SM \& AntunesRodrigues J (1995). Oxytocin mediates atrial natriuretic peptide release and natriuresis after volume expansion in the rat. Proceedings of the National Academy of Sciences, USA, 92: 7902-7906.

14. Lichardus B \& Ponec J (1973). On the role of the hypophysis in the renal mechanism of body fluid volume regulation. Endokrinologie, 61: 403-412.

15. Balment RJ, Brimble MJ, Forsling $M L \&$ Musabayane CT (1986). The influence of neurohypophysial hormones on renal function in the acutely hypophysectomized rat. J ournal of Physiology, 381: 439452.

16. Balment RJ, Brimble MJ, Forsling ML, Kelly LP \& Musabayane CT (1986). A synergistic effect of oxytocin and vasopressin on sodium excretion in the neurohypophysectomized rat. J ournal of Physiology, 381: 453-464.

17. Conrad KP, Gellai M, North WG \& Valtin H (1993). Influence of oxytocin on renal hemodynamics and sodium excretion. Annals of the New York Academy of Sciences, 689: 346-362.

18. Conrad KP, Gellai M, North WG \& Valtin H (1986). Influence of oxytocin on renal hemodynamics and electrolyte and water excretion. American J ournal of Physiology, 251: F290-F296.

19. Stier J r CT, Manning $M \&$ Sawyer WH (1980). Natriuretic effect of [7-glycine]oxytocin in the presence of diuretic agents in conscious rats. J ournal of Pharmacology and Experimental Therapeutics, 212: 412-417.

20. Inoue $T$, Naruse $M$, Nakayama $M$, Kurokawa K \& Sato T (1993). Oxytocin affects apical sodium conductance in rabbit cortical collecting duct. American J ournal of Physiology, 265: F487-F503.

21. Adachi S \& Oku M (1995). The regulation of oxytocin receptor expression in human myometrial monolayer culture. J ournal of Smooth Muscle Research, 31: 175-187.

22. Chan WY \& Sawyer WH (1961). Saluretic actions of neurohypophysial peptides in conscious dogs. American J ournal of Physiology, 201: 799-803.

23. Sedlakova E, Lichardus B \& Cort JH (1969). Plasma saluretic activity: its nature and relation to oxytocin analogs. Science, 164: 580-582.

24. Gutkowska J \& Nemer M (1989). Structure, expression, and function of atrial natriuretic factor in extraatrial tissues. Endocrine Reviews, 10: 519-536.

25. Sudoh $T$, Kangawa $K$, Minamino $N$ \& Matsuo H (1988). A new natriuretic peptide in porcine brain. Nature, 332: 78-81.

26. Sudoh $\mathrm{T}, \mathrm{Minamino} \mathrm{N}$, Kangawa $\mathrm{K} \&$ Matsuo H (1990). C-type natriuretic peptide (CNP): a new member of natriuretic peptide family identified in porcine brain. Biochemical and Biophysical Research Communications, 168: 863-870.

27. Abell TJ, Richards AM, Ikram H, Espiner EA \& Yandle T (1989). Atrial natriuretic factor inhibits proliferation of vascular smooth muscle cells stimulated by platelet-derived growth factor. Biochemical and Biophysical Research Communications, 160: 1392-1396.

28. Jamison RL, Canaan-Kuhl $\mathrm{S} \&$ Pratt $\mathrm{R}$ (1992). The natriuretic peptides and their receptors. American J ournal of Kidney Diseases, 20: 519-530.

29. Suga $S$, Nakao $K$, Itoh $H$, Komatsu $Y$, Ogawa Y, Hama N \& Imura H (1992). Endothelial production of C-type natriuretic peptide and its marked augmentation by transforming growth factor $B$ - Possible existence of vascular natriuretic peptide system. J ournal of Clinical Investigation, 90: 1145-1149.

30. J ankowski M, Reis AM, M ukaddam-Daher S, Dam TV, Farookhi R \& Gutkowska J (1997). C-type natriuretic peptide and the guanylyl cyclase receptors in the rat ovary are modulated by the estrous cycle. Biology of Reproduction, 56: 59-66.

31. Stingo HJ , Clavell AL, Aarhus LL \& Burnett J r J C (1992). Cardiovascular and renal actions of C-type natriuretic peptide. American J ournal of Physiology, 262: H308$\mathrm{H} 312$.

32. Samson WK, Huang $\mathrm{FL} \&$ Fulton RJ (1995). Opposing neuroendocrine actions of the natriuretic peptides: C-type and Atype natriuretic peptides do not interact with the same hypothalamic cells controlling prolactin secretion. J ournal of Neuroendocrinology, 7: 759-763.

33. Samson WK, Skala KD \& Huang FL (1991). CNP-22 stimulates, rather than inhibits, 
water drinking in the rat: evidence for a unique biological action of the C-type natriuretic peptides. Brain Research, 568: 285-288.

34. Hamet P, Tremblay J , Pang SC, Garcia R, Thibault G, Gutkowska J, Cantin M \& Genest J (1984). Effect of native and synthetic atrial natriuretic factor on cyclic GMP. Biochemical and Biophysical Research Communications, 123: 515-527.

35. Chinkers M, Garbers DL, Chang MS, Lowe DG, Chin H, Goeddel DV \& Schulz S (1989). A membrane form of guanylate cyclase is an atrial natriuretic peptide receptor. Nature, 338: 78-83.

36. Lowe DG, Chang MS, Hellmiss R, Chen E, Singh S, Garbers DL \& Goeddel DV (1989). Human atrial natriuretic peptide receptor defines a new paradigm for second messenger signal transduction. EMBO J ournal, 8: 1377-1384.

37. Suga S, Nakao K, Hosoda K, Mukoyama M, Ogawa Y, Shirakami G, Arai H, Saito Y, Kambayashi Y, Inouye K \& Imura H (1992). Receptor selectivity of natriuretic peptide family, atrial natriuretic peptide, brain natriuretic peptide, and C-type natriuretic peptide. Endocrinology, 130: 229-239.

38. Maack $T$, Suzuki $M$, Almeida FA, Nussenzveig D, Scarborough RM, McEnroe GA \& Lewicki J A (1987). Physiological role of silent receptors of atrial natriuretic factor. Science, 238: 675-678.

39. Anand-Srivastava MB, Gutkowska J \& Cantin M (1991). The presence of atrial natriuretic factor receptors of ANF-R2 subtype in rat platelets. Coupling to aden- ylate cyclase/cyclic AMP signal-transduction system. Biochemical J ournal, 278: 211-217.

40. Kaufman $S \&$ Deng $Y$ (1985). Renal response to atrial stretch during pregnancy in conscious rats. American J ournal of Physiology, 17: R271-R281.

41. Ledsome J R, Wilson N, Courneya CA \& Rankin AJ (1985). Release of atrial natriuretic peptide by atrial distension. Canadian J ournal of Physiology and Pharmacology, 63: 739-742.

42. Christensen G (1993). Release of atrial natriuretic factor. Scandinavian J ournal of Clinical and Laboratory Investigation, 53: 91-100.

43. Matsubara $\mathrm{H}$, Hirata $\mathrm{Y}$, Yoshimi $\mathrm{H}$, Takata S, Takagi Y, Umeda Y, Yamane Y \& Imada M (1988). Role of calcium and protein kinase $C$ in ANP secretion by cultured rat cardiocytes. American J ournal of Physiology, 255: $\mathrm{H} 405-\mathrm{H} 409$.

44. Saito $Y$, Nakao $K$, Morii $N$, Sugawara $A$, Shiono S, Yamada T, Itoh $\mathrm{H}$, Sakamoto M, Kurahashi K, Fujiwara M \& Imura H (1986). Bay K 8644, a voltage-sensitive calcium channel agonist, facilitates secretion of atrial natriuretic polypeptide from isolated perfused rat hearts. Biochemical and Biophysical Research Communications, 138: 1170-1176.

45. J irikowski GF, Back H, Forssmann WG \& Stumpf WE (1986). Coexistence of atrial natriuretic factor (ANF) and oxytocin in neurons of the rat hypothalamus. Neuropeptides, 8: 243-249.

46. Huang W, Lee SL \& Sjoquist M (1995).
Natriuretic role of endogenous oxytocin in male rats infused with hypertonic $\mathrm{NaCl}$. American J ournal of Physiology, 268: R634-R640.

47. Schiffrin EL, Franks DJ \& Gutkowska J (1985). Effect of aldosterone on vascular angiotensin II receptors in the rat. Canadian J ournal of Physiology and Pharmacology, 63: 1522-1527.

48. Gutkowska J, J ankowski M, Lambert C, Mukaddam-Daher S, Zingg HH \& McCann SM (1997). Oxytocin releases atrial natriuretic peptide by combining with oxytocin receptors in the heart. Proceedings of the National Academy of Sciences, USA, 94 11704-11709.

49. Adan RA, Van Leeuwen FW, Sonnemans MA, Brouns M, Hoffman G, Verbalis J G \& Burbach J P (1995). Rat oxytocin receptor in brain, pituitary, mammary gland, and uterus: partial sequence and immunocytochemical localization. Endocrinology, 136: 4022-4028.

50. Adan RA, Van Leeuwen FW, Sonnemans MA, Hoffman G, Verbalis J G \& Burbach JP (1995). The rat oxytocin receptor. cDNA cloning and immunocytochemical localization in brain, pituitary, mammary gland and uterus. Advances in Experimental Medicine and Biology, 395: 345-346.

51. J ankowski M, Hajjar F, Al Kawas S, Mukaddam-Daher S, Hoffman G, McCann SM \& Gutkowska J (1998). Rat heart: a site of oxytocin production and action. Proceedings of the National Academy of Sciences, USA, 95: 14558-14563. 